E3S Web of Conferences 1, 20004 (2013)

DOI: $10.1051 / \mathrm{e} 3 \operatorname{sconf} / 20130120004$

(c) Owned by the authors, published by EDP Sciences, 2013

\title{
Characterisation and modelling of mercury speciation in urban air affected by gold mining - assessment of bioavailability
}

\author{
E. M. Cukrowska, J. Lusilao-Makiese, B. Yalala, H. Tutu and L. Chimuka \\ University of the Witwatersrand, Johannesburg, South Africa, ewa.cukrowska@wits.ac.za
}

\begin{abstract}
The growing global concern over the release of mercury to the environment has prompted specific inventories that quantify mercury emissions from various sources. Investigations of atmospheric mercury have been mostly done on gaseous species. Although, to assess human expose to mercury, especially in urban areas, the inhalable dust should be included in a study. The Witwatersrand Basin in South Africa is one of the most important gold mining regions in the world. Mercury $(\mathrm{Hg})$, which occurs in gold-bearing ores, was also used for gold recoveries in previous centuries $\left(19^{\text {th }}\right.$ and early $20^{\text {th }}$ century) and presently in illegal artisanal mining. The consequences of these mining activities were the release of $\mathrm{Hg}$ to the environment, mainly due to AMD from tailings dumps which are presently reprocessed. The city of Johannesburg is a multimillion population exposed strongly to industrial pollution. The aim of this study was to determine the magnitude of mercury pollution in this urban area and assess its bioavailability. The gaseous samples were collected by trapping mercury on various gold traps. Dust samples were collected from a ground and on inhalation levels (1-2 m above a ground). They were later separated into different fractions by micro sieving. Bioavailability of mercury in inhalable dust $(25 \mu \mathrm{m})$ was tested by leaching collected samples with artificial lung fluid (ALF, pH 4.5), Gray's solution ( $\mathrm{pH}$ 7.4) and water. The leaching conditions were selected to mimic lungs environment (incubator at $30^{\circ} \mathrm{C}$, time $24 \mathrm{hrs}$, rotation of samples $150 \mathrm{rpm}$ ). Total concentrations of mercury in dust fractions were also determined after microwave digestion. The results showed extremely high concentration levels of mercury in air and dust in industrial areas. Especially high levels were found around presently reprocessed old gold tailings dumps, up to $900000 \mu \mathrm{gl}^{-1}$. The levels dropped significantly in CBD area but still showing elevated concentrations up to $10 \mu \mathrm{gl}^{-1}$. They depend strongly on prevailing wind directions, dry and wet seasons, and day time. Leaching experiments showed that the Gray's solution extracts more mercury from the dust followed by ALF and much lower by water. This suggests that most of the mercury inhaled with dust will be extracted in the deep interstitial parts of the lungs. In the upper region of lungs extraction will occur to a lesser extent.
\end{abstract}

